\title{
Teaching and Learning DC-DC Converter Design Using MathCAD
}

\author{
Taufik
}

\begin{abstract}
This paper presents an approach for teaching and learning dc-dc converter design using MathCAD. MathCAD provides advantages that greatly improve teaching and learning process especially when long and complicated design equations are involved such as those found in dc-dc converters. A design example using Excel is presented and then compared with the same example using MathCAD. Experience learned from using MathCAD in power electronic courses at Cal Poly will be discussed in this paper.
\end{abstract}

\section{INTRODUCTION}

Power Electronics is a technology which deals with the processing of electrical energy from one form to another in the most efficient manner. At Cal Poly State University, we currently offer three power electronic courses as technical electives for our undergraduate students majoring in Electrical Engineering. The first course, numbered EE 410, is an introductory course with lab component where students learn the basic concepts and designs of power electronic circuits. One major topic of the course is the dc-dc converter.

Dc-dc converter is a widely used power electronic application found in consumer and portable electronics. In the EE 410 course, students learn the design of several dc-dc converter topologies including one major challenge in properly selecting circuit components to minimize converter's losses. In practice each component is usually available from several manufacturers in various packages and configurations. In turns, this complicates the selection process since one component produced by several manufacturers will yield several loss equations. Teaching and learning such repetitive design process in a classroom environment poses a challenge and becomes impractical. Assigning homework to practice the design procedure will be a lengthy and tedious one, especially if done by hand calculations. One way to overcome this problem is to use a software tool. EXCEL is an example of widely used software at companies and schools for engineering design tool [7] [8] [9] [2]. However, Excel spreadsheets inherently posses a serious disadvantage with the use of cell names and numbers which causes complexity surrounding formulas and their arguments, and lack of detail in error messages [1] [3]. The MathCAD software on the other hand enables users to type in equations (symbolic programming) as they appear on the paper. The many advantages of using MathCAD such as the showing of units, array processing and others have been mentioned in [5], [4] and [6].

\section{DESIGN EXAMPLE USING EXCEL AND MATHCAD}

One dc-dc converter circuit discussed in depth in the EE 410 course is the step down converter (Figure 1). Despite its simple configuration, circuit's complexity lies on the careful selection of its components to satisfy operating and efficiency requirements.

The basic or ideal design equations to select the main components of the circuit with proper voltage and current ratings are readily available and are in general straight forward. For example, to determine the minimum voltage rating of the component Q1, one needs to know only the input voltage VI to the circuit. The same is true for the minimum voltage rating of components CR1 and C1. Sizing component L1 takes a little bit more work since one needs to know more than one design constraint. Once nominal values and ratings of all components are computed, the next step is to find all components available in the market that will opti- 
mize the results. This is a repetitive process since more often than not, the components are either out of stock or they are not available at all. When this happens, the component selection process starts all over again.

To illustrate the benefits of using MathCAD, design equations to determine the ratings of the main components will first be implemented using commonly available software called Excel. Figure 2 shows an Excel sheet that implements the Buck design equations. Although Excel presents the results of design equations well, it does not immediately show all equations used. The equations are 'hidden' under each cell and behind cell numbers and cell names, thus lengthening the already long design process. Furthermore, it causes difficulties for students to quickly assess the impact of any parameter in the design to the component ratings. The use of cell numbers in design equations adds the extra step to understanding the design, and in particular becomes cumbersome and hard to follow when long design equations are involved. As a result, using excel as a tool in this case increases the time to learn the design process.

From instructor's perspective, due to time constraint, it will not be practical to actually go through each cell when explaining each design equation and how they are related to each other. Another drawback is the lack of mechanism to check if the equation typed in each cell is correct or if a value resulting from a design equation has the right unit. In figure 2 , the units were manually entered.

These shortcomings of Excel may be avoided with the use of MathCAD. Figure 3 illustrates the same design example using MathCAD. Design equations in MathCAD are entered symbolically just as users would write them on a piece of paper. This will not only make the presentation of the design sheet much more intuitive, but will also greatly reduce the time spent in discussing the design equations in class. Unlike Excel, students may now see immediately the impact of any design parameters. Another useful feature of MathCAD is the provision of unit following every calculated result. Therefore, if a design equation was accidentally mistyped or not correct, then the error can be quickly seen from the undesired unit of the result. When a parameter has not been defined previously, MathCAD will immediately highlight the parameter in red. This will further shorten the troubleshooting process.

\section{CONCLUSIONS}

In this paper, one approach of teaching and learning dc-dc converter design using MathCAD has been described. Experience learned from using MathCAD shows that 99\% of students taking EE 410 prefer to use MathCAD than Excel. Students feel that MathCAD provides a more intuitive presentation of the design equations and hence improves their understanding of the subject. A major concern of Math-CAD, however, is the lack of a free version. The cost of student version is currently over $\$ 100$ and therefore not economically attractive for students.

\section{REFERENCES}

[1] Online: http://www.jegsworks.com/Lessons/numbers/ design/step-usingif.htm.

[2] Onsemi excel design tool. Online: http://www.onsemi.com/PowerSolutions/ supp ortDoc. do?type=tools.

[3] Using spreadsheets to enhance teaching and learning. Online: http://www.tcet.unt.edu/weblibrary/ppt/teachss.ppt.

[4] K. A. Ansari. An Introduction to Numerical Methods Using Mathcad Mathcad Release 13. SDC Publications, first edition edition, 2006.

[5] K. P. Brannan and J. A. Murden. From c++ to mathcad: Teaching an introductory computer programming course with a non-traditional programming language. In ASEE National Conference Proceedings, Jun 1998.

[6] C. Domnisoru. Using mathcad in teaching power engineering. IEEE Transactions On 
Education, 48, Feb 2005.

[7] J. Freeman and S. Rositano. A freshman design \& engineering tools course. In Proceedings of Frontiers in Education Conference, 1995.

[8] B. Gottfried. Spreadsheet Tools for Engineers Using Excel. McGraw-Hill, first edition edition, 2005.

[9] R. Larsen. Engineering With Excel. Prentice-Hall, 2001.

\section{Figures}

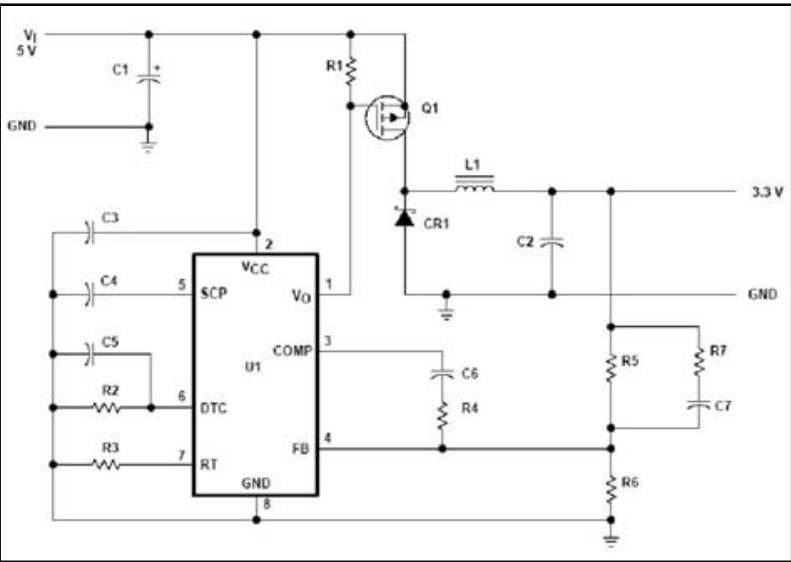

Figure 1: Buck converter schematic

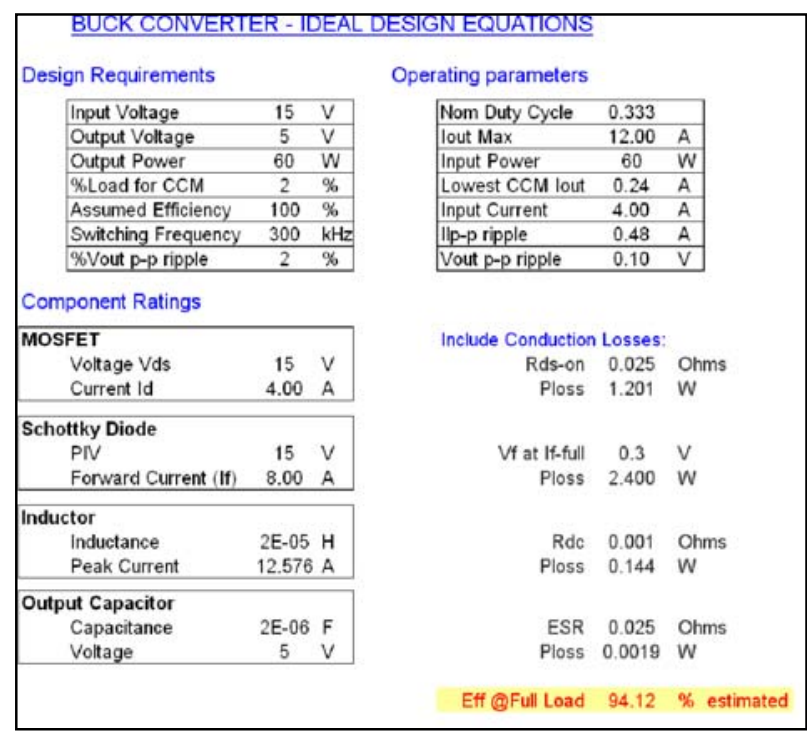

Figure 2: Excel design sheet for Buck converter 


\begin{tabular}{|c|c|c|c|c|}
\hline \multicolumn{5}{|c|}{ BUCK CONVERTER - IDEAL DESIGN EQUATIONS } \\
\hline \multirow[t]{2}{*}{ Design Requirements } & $\mathrm{Vin}=15 \mathrm{~V}$ & $\mathrm{~V}_{0}=5 \mathrm{~V}$ & $P_{0}=60 \mathrm{~W}$ & $\mathrm{Fe}=300 \mathrm{kHz}$ \\
\hline & $\mathrm{Iecm}=2 \%$ & $\eta=100 \%$ & Vepp $:=2 \%$ & \\
\hline \multicolumn{5}{|c|}{ Operating Parameters: } \\
\hline \multicolumn{2}{|c|}{ Nominal Dury Oycle: } & \multicolumn{2}{|l|}{ Dnom $:=\frac{V_{0}}{V_{u n}}$} & Dnom $=0.333$ \\
\hline \multicolumn{2}{|c|}{ Max Output Curent } & \multicolumn{2}{|l|}{ Ions $=\frac{P_{0}}{V_{0}}$} & Iomax $=12 \mathrm{~A}$ \\
\hline \multicolumn{2}{|l|}{ Input Power. } & \multicolumn{2}{|l|}{$\mathrm{P}_{\mathrm{n}}=\frac{\mathrm{P}_{0}}{\eta}$} & $\mathrm{Pin}=60 \mathrm{~W}$ \\
\hline \multicolumn{2}{|c|}{ Lowest CCM Current } & \multicolumn{2}{|c|}{ Iccmamp := Iccm Iomax } & Iccmamp $=0.24 \mathrm{~A}$ \\
\hline \multicolumn{2}{|c|}{ Average Input Current } & \multicolumn{2}{|l|}{ In $=\frac{P_{\text {in }}}{V_{\text {in }}}$} & In $=4 \mathrm{~A}$ \\
\hline \multicolumn{2}{|c|}{ Peak to Peak Vout } & \multicolumn{2}{|c|}{ Vopprot: $=V_{o p p} \cdot V_{0}$} & Vopproit $=01 \mathrm{~V}$ \\
\hline \multicolumn{5}{|c|}{ Component Ratings: } \\
\hline \multirow[t]{2}{*}{ MOSFET: } & Voltage Rating & \multicolumn{2}{|l|}{$V d s:=V_{\text {In }}$} & $\mathrm{Vds}=15 \mathrm{~V}$ \\
\hline & Current Retng & \multicolumn{2}{|c|}{ Id $=$ Dnom - Iomax } & $I d=4 \mathrm{~A}$ \\
\hline \multirow[t]{2}{*}{ Schotthy: } & Voltage Rating & \multicolumn{2}{|l|}{ PIV $=V_{\text {In }}$} & $\mathrm{PIV}=15 \mathrm{~V}$ \\
\hline & Current Reting & \multicolumn{2}{|c|}{ If $=(1-$ Drom $)$ Iomax } & $I=8 \mathrm{~A}$ \\
\hline \multirow[t]{2}{*}{ Inductor: } & lnductance & \multicolumn{2}{|c|}{$L=\frac{(1-\text { Drom }) \cdot V_{0}}{2 \cdot F_{s} \text { Iecmamp }}$} & $\mathrm{L}=2.315 \times 10^{-5} \mathrm{H}$ \\
\hline & Paak Current & \multicolumn{2}{|c|}{$I_{P}:=\operatorname{Iomax}+\frac{\left(1-D_{0} \circ m\right) \cdot V_{0}}{2 \cdot L \cdot F s}$} & $\mathbb{I}_{\mathrm{P}}=12.24 \mathrm{~A}$ \\
\hline \multirow[t]{2}{*}{ Capacitor: } & Voltage: & \multicolumn{2}{|c|}{$V_{c a p}:=V_{0}+\frac{V_{\text {oppysle }}}{n}$} & $\mathrm{~V} c \mathrm{cap}=5.05 \mathrm{~V}$ \\
\hline & Cepacitance & \multicolumn{2}{|c|}{$C_{0}=\frac{(1-\text { Drom })}{8 L F_{3}^{2} \cdot \text { Vopp }}$} & $\mathrm{C}_{0}=2 \times 10^{-6} \mathrm{~F}$ \\
\hline
\end{tabular}

Figure 3: MathCAD design sheet for Buck converter 